\title{
Increased Serum Procollagen Type I C-terminal Propeptide Levels are Associated with Subclinical Left Ventricular Dysfunction in Patients with Breast Cancer Treated with Anthracycline-Based Cancer Chemotherapy
}

\section{Ana de la Fuente}

Clínica Universidad de Navarra: Clinica Universidad de Navarra

\section{Marta Santisteban}

Clinica Universidad de Navarra Departamento de Oncología Médica: Clinica Universidad de Navarra Departamento de Oncologia Medica

Josep Lupón

Hospital Universitari Germans Trias i Pujol

José Manuel Aramendía

Clinica Universidad de Navarra Departamento de Oncología Médica: Clinica Universidad de Navarra Departamento de Oncologia Medica

Agnes Díaz

Clinica Universidad de Navarra

Germán Cediel

Hospital Universitari Germans Trias i Pujol

Begoña López

CIMA Universidad de Navarra

José María López Picazo

Clinica Universidad de Navarra Departamento de Oncología Médica: Clinica Universidad de Navarra Departamento de Oncologia Medica

\section{Gregorio Rábago}

Clinica Universidad de Navarra

Javier Díez

Clinica Universidad de Navarra

Arantxa González

CIMA Universidad de Navarra

Antoni Bayés-Genís

Hospital Universitari Germans Trias i Pujol

Susana Ravassa ( $\sim$ sravassa@unav.es ) 


\section{Research article}

Keywords: Anthracycline-based chemotherapy, cardiotoxicity, global longitudinal strain, left ventricular ejection fraction, myocardial fibrosis, biomarkers

Posted Date: November 6th, 2020

DOl: https://doi.org/10.21203/rs.3.rs-101186/v1

License: (c) (i) This work is licensed under a Creative Commons Attribution 4.0 International License. Read Full License 


\section{Abstract}

Background Anthracycline-based cancer chemotherapy (ACC) has been related to myocardial interstitial fibrosis (MIF), a lesion contributing to left ventricular dysfunction (LVD). We investigated whether biomarker-assessed MIF was associated with LVD in patients with breast cancer receiving ACC and in patients with ACC-induced heart failure (ACC-HF). Moreover, chemotherapy agent's pro-fibrotic activity was evaluated in human cardiac fibroblasts (HCFs).

Methods Echocardiography, serum biomarkers of collagen deposition (procollagen type-I C-terminalpropeptide [PICP]) and crosslinking (collagen type-I C-terminal-telopeptide/matrix metalloproteinase-1 ratio), and biomarkers of myocardial and vascular stress (galectin-3, sST2, amino-terminal pro-brain natriuretic peptide [NT-proBNP], hs-troponin-T and vascular cell adhesion molecule-1 [VCAM-1]) were assessed in 70 breast cancer patients at baseline, and during ACC at 3 and 6 months. Subclinical cardiotoxicity was defined as global longitudinal strain (GLS) relative reduction $>15 \%$. In addition, PICP and NT-proBNP were determined in 347 patients with different HF etiologies, 37 with ACC-HF (of whom $65 \%$ had been diagnosed with breast cancer) and 12-month-follow-up LVEF assessment. HCFs activation was examined after incubation with doxorubicin, cyclophosphamide, paclitaxel and trastuzumab for 24 hours.

Results In patients with breast cancer, six-months-ACC reduced GLS and upregulated PICP, hs-troponin-T, NT-proBNP and VCAM-1 $(P<0.01)$ versus baseline. At 6 months, elevation of PICP was higher in patients with subclinical cardiotoxicity versus the remaining patients ( $P$ for interaction<0.001). PICP levels were directly and independently associated with a relative reduction in GLS $(P<0.001)$. In ACC-HF patients, baseline LVEF was inversely associated with PICP and NT-proBNP $(P<0.01)$. After 12 months, LVEF did not change in patients with higher basal PICP ( $3^{\text {rd }}$ tertile) but improved in the remaining patients $(P<0.001)$. Doxorubicin, cyclophosphamide and trastuzumab stimulated collagen synthesis in HCFs.

Conclusion These results indicate that biomarker-assessed MIF associates with early LVD in ACC-treated patients with breast cancer. In addition, these findings suggest that MIF may be associated with established LVD in ACC-HF patients, hindering LV functional improvement after 12 months. Finally, chemotherapy can directly activate collagen metabolism in HCFs.

\section{Introduction}

Highly-effective oncologic drugs have led to important improvements in survival rates in patients with breast cancer. However, these agents are associated with side effects, cardiotoxicity among them, which limits treatment options and contributes to morbidity and mortality in these patients [1-4]. Therefore, there is a critical need to understand the pathophysiological mechanisms taking place in the myocardium of patients undergoing cancer chemotherapy before irreversible cardiac damage occurs [5].

Traditionally, cardiotoxicity due to breast cancer treatment, particularly anthracycline-based cancer chemotherapy (ACC), has been attributed to cardiomyocyte damage and death, with amino-terminal pro- 
brain natriuretic peptide (NT-proBNP) and high-sensitivity troponins (hs-Tn) as the most commonly used biomarkers to detect cardiac damage in these patients $[5,6]$. However, it has been suggested that myocardial interstitial fibrosis (MIF) is an additional important mechanism contributing to left ventricular dysfunction (LVD) and adverse clinical evolution in ACC-treated patients [6, 7], as well as in patients treated with other oncologic drugs such as cyclophosphamide, taxane agents and anti-HER2 therapies [8-14]. As cumulative evidence suggest that the detrimental impact of MIF on LV function is related to both an excess in collagen type-I fiber cross-linking and deposition [15], these characteristics of the collagen fiber should be evaluated in the myocardium of patients receiving ACC. In this regard, some circulating peptides with histologically-proven association with MIF have been described. On the one hand, the serum procollagen type-I C-terminal propeptide (PICP), released during the conversion of procollagen type-l into fibril-forming mature collagen type-I, is directly correlated with LV myocardial collagen type-I deposition [16]. On the other hand, the ratio of serum collagen type-I C-terminal telopeptide to serum matrix metalloproteinase-1 (CITP:MMP-1) is inversely correlated with LV myocardial collagen type-I cross-linking, as the higher is the cross-linking among collagen type-l fibrils, the lower will be the cleavage of CITP by MMP-1 during the process of fiber degradation [17].

Therefore, we propose to investigate whether ACC induces biomarker-assessed MIF and whether this lesion is associated with early LVD in patients with breast cancer undergoing chemotherapy and with established LVD in patients with ACC-induced heart failure (ACC-HF). To address these questions, we have analyzed 3- and 6-month changes in the levels of serum PICP and CITP:MMP-1, and of other biomarkers associated with myocardial remodeling (e.g., vascular cell adhesion molecule-1 [VCAM-1], galectin-3 and soluble ST2 [sST2]) and injury-dysfunction (e.g., NT-proBNP and hs-TnT), in breast cancer patients undergoing ACC. In addition, we have evaluated biomarkers of MIF and injury-dysfunction in patients with ACC-HF in whom LV function has been re-assessed after 12 months follow-up. Finally, to characterize the pro-fibrotic mechanisms of breast cancer chemotherapy drugs, we have performed in vitro studies to analyze several aspects related to collagen metabolism in human cardiac fibroblasts (HCFs) incubated with these compounds.

\section{Methods}

All procedures performed in studies involving human participants were in accordance with the ethical standards of the Clinical Investigation Ethics Committees of the University of Navarra and of the Hospital Universitari Germans Trias i Pujol. The study conformed to the principles of the Helsinki Declaration of 1975, as revised in 2013.

\section{Study 1: Patients with breast cancer}

Samples from patients included in the study were provided by the Biobank of the University of Navarra and were processed following standard operating procedures approved by the Clinical Investigation Ethics Committee of the University of Navarra. 


\section{Study population}

Eighty-one patients with treatment-naive primary breast cancer were prospectively recruited from 2017 to 2019 in the Breast Cancer Unit at the department of Medical Oncology at the University of Navarra Clinic. A total of 70 patients with planned treatment with epirubicin/cyclophosphamide and taxanes were eligible for inclusion (mean age 50.8 years, range 32-81 years). Reasons for exclusion included loss to follow-up $(n=7)$, incomplete baseline and follow-up data $(n=2)$ and unwillingness or inability to provide informed consent $(n=2)$. Epirubicin cumulative dose was $<300 \mathrm{mg} / \mathrm{m} 2$ in 18 patients and 300$400 \mathrm{mg} / \mathrm{m} 2$ in 52 patients. Twenty-three patients underwent surgery before chemotherapy and received adjuvant chemotherapy. The remaining patients received neoadjuvant chemotherapy before surgery procedure. Eighteen patients with HER2 overexpressing breast cancer received, in addition, targeted therapy (trastuzumab \pm pertuzumab) administered concomitantly with taxanes. No patient had history of congenital heart disease, coronary heart disease, heart valve disease, heart failure or left ventricular ejection fraction (LVEF) $<50 \%$.

\section{Study protocol}

Participants were studied before chemotherapy (baseline) and at standardized intervals after epirubicin/cyclophosphamide treatment at 3 months (visit 1) and after taxane treatment, with or without anti-HER2 therapy, at 6 months (visit 2). Transthoracic echocardiography, biochemical analyses and circulating biomarker determinations were performed at baseline, visit 1 and visit 2 (Fig. 1A). For further details see the Online Supplement.

Early subclinical cardiotoxicity was defined as a relative decrease in 2D global longitudinal strain (GLS, as assessed by speckle-tracking analysis) $>15 \%$ versus baseline [18], and established cardiotoxicity as an asymptomatic decrease in LVEF $>15 \%$ or an asymptomatic decrease of LVEF $>10 \%$ to an absolute value $<53 \%$ versus baseline $[18,19]$.

\section{Study 2: Patients with HF}

\section{Study population}

The source of the study population from which this cohort is derived has been described elsewhere [20]. In summary, all patients were ambulatory HF patients treated at a multidisciplinary unit from the Division of Cardiology at the Hospital Universitari Germans Trias i Pujol (Badalona, Spain). The principal referral criterion was HF according to the European Society of Cardiology guidelines irrespective of etiology, at least one HF hospitalization, and/or reduced LVEF. The present cohort inclusion criteria were baseline echocardiogram and biomarker measurement.

Three hundred and forty seven HF patients at baseline were categorized according to etiologies, 37 with ACC-HF of whom twenty-four (64.9\%) had been diagnosed with breast cancer. In these patients, the presence of cardiovascular comorbidities was further examined to exclude causes other than ACC therapy as the main driver of symptomatic HF. For further details see the Online Supplement. 


\section{Circulating Biomarkers}

Circulating PICP, NT-proBNP, hs-TnT, galectin-3 and VCAM-1 were measured using commercial ELISAs. SST2 and MMP-1 were measured using an EIA and an alphaLISA, respectively. CITP was measured using a RIA. For further details see the Online Supplement.

Study 3: In vitro experiments

\section{Cell Culture}

Adult human dermal fibroblasts (HDF) and primary cell cultures of HCFs were incubated with either vehicle or the chemotherapy agents doxorubicin, cyclophosphamide, paclitaxel and trastuzumab for $24 \mathrm{~h}$. Primary cell cultures of HCFs were isolated from atrial samples obtained as discarded surgical tissue by mechanical and tissue enzymatic digestion with collagenases and characterized (i.e. vimentin staining) as previously described [21]. In addition, all cell cultures were tested for fibrotic response (increased mRNA procollagen type I expression) to the transforming growth factor-beta 1. All patients gave written informed consent to donate the tissue, and the Institutional Review Committee approved the study protocol. The study conformed to the principles of the Helsinki Declaration. Cells were left to expand until they reached $60 \%$ confluence. Cells were then starved in reduced serum medium for $24 \mathrm{~h}$ prior to stimulation with chemotherapy agents for another $24 \mathrm{~h}$. The number of viable cells were determined upon trypan blue staining and counted in a Neubauer chamber. For further details see the Online Supplement.

\section{Quantitative-Real-time PCR}

Gene expression was analysed by quantitative real-time PCR by using specific TaqMan fluorescent probes. For further details see the Online Supplement.

\section{Extracellular collagen content}

Collagen content in the supernatants of HCFs was estimated by quantification of hydroxyproline in accordance with the intructions for the QuickZyme Total Collagen Assay (QuickZyme Biosciences). Data were normalized to viable cell number and expressed as fold change versus unstimulated cells.

\section{Extracellular PICP content}

PICP in the supernatants of HCFs was quantified using the alphaLISA PIP (PerkinElmer). The inter-assay and intra-assay coefficients of variation were $<1 \%$. The lower limit of detection was $12 \mathrm{pg} / \mathrm{mL}$. Data were normalized by viable cell number and expressed as fold change versus unstimulated cells.

\section{LOX activity}

LOX activity in the supernatants of HCFs was measured with a commercially available fluorimetric assay (AAT Bioquest) following the manufacture's indications as previously described [22]. Data were normalized by viable cell number and expressed as fold change versus unstimulated cells.

\section{Statistical analysis}


Non-normally distributed variables were examined after logarithmic transformation. Differences between two groups of subjects were tested by Student's $t$ test for unpaired data once normality was demonstrated. Otherwise, a nonparametric test (Mann-Whitney U test) was used. Differences among three groups or more were tested by one-way ANOVA followed by Bonferroni's post-hoc comparisons tests in case normality was demonstrated. Otherwise, a Kruskal-Wallis test was performed followed by MannWhitney $U$ test with Bonferroni correction. Categorical variables were analyzed by the chi-squared test or Fisher's exact test when necessary. Baseline associations were examined by linear regression. Mixedeffects regression modelling was used for longitudinal and association analyses. Individual linear mixedeffects models with a random intercept to account for intraparticipant correlation of repeated measures were used to estimate changes across visits. In patients with breast cancer, subclinical cardiotoxicity at visit 2, visit, their interaction term, and baseline values of the dependent variable were added as fixed effects to examine whether the development of subclinical cardiotoxicity was accompanied by greater changes in the parameters of interest as compared with its absence over time. Visit as random slope was allowed if the model was significantly better fitted compared to a model with only random intercept. The variance component structure was specified according to the best fit model. The likelihood ratio test and Akaike information criterion were used to select the model with the best fit. To examine the independent association between PICP and GLS, confounding variables with $\mathrm{P}$ values $<.10$ in univariate analyses, including baseline GLS values, were considered in the multivariable analysis. Multicollinearity was defined as variance inflation factor (VIF) $>5$ with model reduction in case any variable showed evidence of multicollinearity. The heteroscedasticity and normality of the residuals were examined by scatterplots and by the Skewness/Kurtosis test, respectively. Logistic regression analyses were used to assess the relationships of the biomarker levels at baseline, or biomarker changes versus baseline or between visits, with the presence of subclinical cardiotoxicity. Optimal cut-off values for predicting the development of subclinical cardiotoxicity at visit 2 were determined by performing receiver-operating characteristic (ROC) curve analysis followed by the calculation of the Younden's $\mathrm{J}$ statistic. The Benjamini and Hochberg multiple test correction (false discovery rate of $5 \%$ ) was applied to all biomarker analyses.

Mixed-effect analyses were performed with the "mixed" command within STATA. Values are expressed as mean \pm SD or median (interquartile range), and categorical variables as numbers and percentages. Statistical significance was set as a 2-sided $P$ of 0.05 . The statistical analyses were performed by using SPSS (15.0 version) and STATA (13.0 version) software.

\section{Results}

\section{Study 1: Patients with breast cancer Characteristics of patients at baseline}

Supplemental Table $\mathrm{S} 1$ shows the clinical characteristics of all patients at baseline. At the time of enrollment, $13(18.6 \%)$ patients had hypertension, $9(12.9 \%)$ were obese, $1(1.4 \%)$ had diabetes, $5(7.1 \%)$ smoked, 2 (2.9\%) had eGFR values $<60 \mathrm{~mL} / \mathrm{min} / 1.73 \mathrm{~m}^{2}$, and $1(1.4 \%)$ had atrial fibrillation. 


\section{Analysis of longitudinal changes with cancer therapy}

\section{All patients}

Effects of chemotherapy on hematological parameters and on renal and liver function parameters in all patients are shown in supplemental Table S2.

Effects of chemotherapy on echocardiographic parameters and biomarkers are shown in Table 1. Of interest, left atrial volume index ( $\mathrm{LAVI})$ and LV end-diastolic and systolic volume indexes as determined by 3D echocardiography increased at visit 2 versus baseline, and a relative reduction of GLS at visit 2 was observed compared with baseline and visit 1 (Table 1). In addition, levels of NT-proBNP, hs-TnT, sST2 and VCAM-1 were increased at visit 1 as compared with baseline (Table 1, Fig. 1B). At visit 2, NT-proBNP, hsTnT and VCAM-1 remained elevated and PICP increased as compared with baseline (Table 1, Fig. 1B). 
Table 1

Longitudinal changes in echocardiographic parameters and in biomarkers

Baseline

Visit 1

Visit 2

\section{Echocardiographic parameters}

2D Echocardiography and $\mathrm{M}$ mode
LVMI, $g / \mathrm{m}^{2}$
$64.5 \pm 14.0$
$70.2 \pm 17.2^{*}$
$67.5 \pm 16.3$
LVH (LVMI > $\left.95 \mathrm{~g} / \mathrm{m}^{2}\right), \mathrm{n}(\%)$
$2(2.9)$
$7(10.0)$
$6(8.6)$
RWT
$0.36 \pm 0.08$
$0.37 \pm 0.07$
$0.36 \pm 0.08$
LVEDVi, $\mathrm{mL} / \mathrm{m}^{2}$
$54.6 \pm 14.5$
$55.6 \pm 14.4$
$56.9 \pm 14.6$
LVEF, \%
$63.9 \pm 5.0$
$64.9 \pm 4.4$
$63.4 \pm 5.5$
E:A ratio
$1.13 \pm 0.35$
$1.10 \pm 0.39$
$1.08 \pm 0.30$
DT, ms
$208 \pm 42.8$
$197 \pm 43.4$
$200 \pm 31.1$
LAVI, $\mathrm{mL} / \mathrm{m}^{2}$
$18.8 \pm 5.9$
$19.8 \pm 8.2$
$21.4 \pm 6.6^{*}$

Tissue Doppler
E:e' ratio
$6.8 \pm 1.9$
$7.3 \pm 2.3$
$7.1 \pm 1.5$

Speckle tracking

GLS, \%

$-20.6 \pm 2.0$

$-20.2 \pm 2.4^{\star}$

$-19.4 \pm 2.4^{\dagger \neq}$

3D Echocardiography

\begin{tabular}{lccc} 
LVEDVi, $\mathrm{mL} / \mathrm{m}^{2}$ & $47.4 \pm 9.3$ & $52.0 \pm 10.3^{\dagger}$ & $50.6 \pm 10.7^{\star}$ \\
\hline LVESVi, $\mathrm{mL} / \mathrm{m}^{2}$ & $17.7 \pm 4.6$ & $19.2 \pm 4.9^{*}$ & $19.9 \pm 6.1^{\dagger}$ \\
\hline LVEF, \% & $62.5 \pm 5.7$ & $62.9 \pm 4.5$ & $61.9 \pm 6.0$
\end{tabular}

LVMI means left ventricular (LV) mass index; LVH, LV hypertrophy; RWT, relative wall thickness; LVEDVi, LV end-diastolic volume index; $E$, maximum early transmitral flow velocity in diastole; $A$, maximum late transmitral flow velocity in diastole; DT, deceleration time; LAVI, left atrial volume index; $e^{\prime}$, maximum early diastolic velocity of the mitral annulus displacement; GLS, global longitudinal strain; LVESVi, LV end-systolic volume index; LVEF, LV ejection fraction. NT-proBNP, amino-terminal pro-brain natriuretic peptide; hs-TnT, high sensitivity troponin T; SST2, soluble suppression of tumourigenicity-2; VCAM-1, vascular cell adhesion molecule-1; PICP, procollagen type I C-terminal propeptide; CITP, collagen type I C-terminal telopeptide; MMP-1, matrix metalloproteinase-1.

Quantitative variables are expressed as mean \pm SD and categorical variables as number (percentage). ${ }^{*} \mathrm{P}<0.05$ vs basal, ${ }^{\dagger} \mathrm{P}<0.01$ vs basal, ${ }^{\ddagger} \mathrm{P}<0.05$ vs visit $1,{ }^{\S} \mathrm{P}<0.01$ vs visit 1.

IIP values in the biomarker analyses were adjusted according to the Benjamini and Hochberg multipletest correction (5\% FDR). 


\section{Biomarkers"}

Cardiomyocyte stress/damage
NTproBNP, pg/mL
$40.2(22.9-64.3)$
$65.2(42.9-118)^{\dagger}$
$58.7(33.3-100)^{\dagger}$
hs-TnT, ng/L
$3.0(3.0-4.5)$
$8.3(3.7-11.0)^{\dagger}$
$7.5(4.6-11.0)^{\dagger}$

Myocardial stress

$\begin{array}{llll}\text { Galectin 3, ng/mL } & 12.8(11.2-14.7) & 12.0(10.8-14.8) & 12.3(10.6-15.0) \\ \text { sST2, ng/mL } & 1184(969-1539) & 1613(1098-3013)^{+} & 1102(893-1429)^{\S}\end{array}$

Endothelial dysfunction

VCAM- $1, \mathrm{ng} / \mathrm{mL}$

$877(740-1106)$

$949(782-1156)^{*}$

$966(789-1183)^{*}$

Myocardial fibrosis

PICP, $n g / m L$

$72.6(59.5-87.5)$

$64.7(54.8-74.0)$

$89.9(70.9-120)^{\dagger \S}$

CITP:MMP-1 ratio

$1.5(1.2-3.1)$

$2.1(1.1-3.7)$

$2.1(1.4-3.8)$

LVMI means left ventricular (LV) mass index; LVH, LV hypertrophy; RWT, relative wall thickness; LVEDVi, LV end-diastolic volume index; E, maximum early transmitral flow velocity in diastole; A, maximum late transmitral flow velocity in diastole; DT, deceleration time; LAVI, left atrial volume index; $e^{\prime}$, maximum early diastolic velocity of the mitral annulus displacement; GLS, global longitudinal strain; LVESVi, LV end-systolic volume index; LVEF, LV ejection fraction. NT-proBNP, amino-terminal pro-brain natriuretic peptide; hs-TnT, high sensitivity troponin T; SST2, soluble suppression of tumourigenicity-2; VCAM-1, vascular cell adhesion molecule-1; PICP, procollagen type I C-terminal propeptide; CITP, collagen type I C-terminal telopeptide; MMP-1, matrix metalloproteinase-1.

Quantitative variables are expressed as mean \pm SD and categorical variables as number (percentage). ${ }^{\star} \mathrm{P}<0.05$ vs basal, ${ }^{\dagger} \mathrm{P}<0.01$ vs basal, ${ }^{\ddagger} \mathrm{P}<0.05$ vs visit $1,{ }^{\S} \mathrm{P}<0.01$ vs visit 1 .

IIP values in the biomarker analyses were adjusted according to the Benjamini and Hochberg multipletest correction (5\% FDR).

Patients categorized according to the presence of subclinical cardiotoxicity at visit 2

Fourteen patients (20.0\%) exhibited subclinical cardiotoxicity at visit 2. Supplemental Table S1 shows the baseline clinical characteristics of patients classified according to the absence or presence of subclinical cardiotoxicity at visit 2. No clinically relevant differences were observed between the two groups of patients at baseline (Supplemental Table S1).

Differences at visit 1 and visit 2 in hematological, renal and liver function parameters between patients with and without subclinical cardiotoxicity are shown in supplemental Table S3. Of interest, patients with 
subclinical cardiotoxicity at visit 2 exhibited lower hemoglobin and hematocrit values at visit 1 than the remaining patients ( $P$ for interaction $\leq 0.018$ ).

Differences at visit 1 and visit 2 in echocardiographic parameters and biomarkers between patients with and without subclinical cardiotoxicity at visit 2 are shown in Table 2. Of interest, patients with subclinical cardiotoxicity exhibited higher PICP levels at visit 2 as compared with the remaining patients $(P$ for interaction $<0.001$ ) (Table 2 and Fig. $2 A$ ). No other interactions were found significant for the remaining biomarkers (Table 2). 
Table 2

Differences in echocardiographic parameters and in biomarkers after treatment with epirubicin/cyclophosphamide (visit 1) followed by treatment with taxanes (visit 2) in patients categorized according to the absence or presence of subclinical cardiotoxicity at visit 2.

Difference vs no cardiotoxicity

P for interaction

Visit 1

$\begin{array}{lll}\text { Difference } & 95 \% & \mathrm{P} \\ \mathrm{Cl} & \text { value }\end{array}$
Visit 2

$\begin{array}{lll}\text { Difference } & 95 \% & \mathrm{P} \\ & \mathrm{Cl} & \text { value }\end{array}$

\section{Echocardiographic parameters}

2D Echocardiography and $M$ mode

\begin{tabular}{|c|c|c|c|c|c|c|c|}
\hline LVMI, g/m² & -4.29 & $\begin{array}{l}-14.3 \\
\text { to } \\
5.68\end{array}$ & 0.40 & -0.31 & $\begin{array}{l}-10.0 \\
\text { to } \\
9.40\end{array}$ & 0.95 & 0.41 \\
\hline RWT & 0.02 & $\begin{array}{l}-0.02 \\
\text { to } \\
0.06\end{array}$ & 0.37 & 0.02 & $\begin{array}{l}-0.04 \\
\text { to } \\
0.07\end{array}$ & 0.54 & 0.69 \\
\hline LVEDVi, $\mathrm{mL} / \mathrm{m}^{2}$ & -2.40 & $\begin{array}{l}-12.0 \\
\text { to } \\
7.19\end{array}$ & 0.62 & -0.65 & $\begin{array}{l}-10.6 \\
\text { to } \\
9.27\end{array}$ & 0.90 & 0.59 \\
\hline LVEF, \% & 0.19 & $\begin{array}{l}-2.30 \\
\text { to } \\
2.67\end{array}$ & 0.88 & -1.46 & $\begin{array}{l}-4.65 \\
\text { to } \\
1.73\end{array}$ & 0.37 & 0.57 \\
\hline E:A ratio & 0.04 & $\begin{array}{l}-0.19 \\
\text { to } \\
0.27\end{array}$ & 0.75 & 0.002 & $\begin{array}{l}-0.14 \\
\text { to } \\
0.14\end{array}$ & 0.98 & 0.78 \\
\hline $\mathrm{DT}, \mathrm{ms}$ & -7.63 & $\begin{array}{l}-28.0 \\
\text { to } \\
12.7\end{array}$ & 0.46 & 5.46 & $\begin{array}{l}-11.6 \\
\text { to } \\
22.5\end{array}$ & 0.53 & 0.55 \\
\hline LAVI, $\mathrm{mL} / \mathrm{m}^{2}$ & -1.68 & $\begin{array}{l}-5.63 \\
\text { to } \\
2.27\end{array}$ & 0.40 & -3.24 & $\begin{array}{l}-7.66 \\
\text { to } \\
1.18\end{array}$ & 0.15 & 0.61 \\
\hline
\end{tabular}

Tissue Doppler

$\begin{array}{llllllll}\mathrm{E}^{\prime} \mathrm{e}^{\prime} & 0.31 & -0.80 & 0.59 & 0.08 & -0.59 & 0.81 & 0.85 \\ & & \text { to } & & & \text { to } & & \\ & 1.41 & & & 0.75 & & \end{array}$

Speckle tracking

Abbreviations as in Table 1.*Significant after Benjamini and Hochberg multiple-test correction (5\% FDR) in the biomarker analyses 


\begin{tabular}{|c|c|c|c|c|c|c|c|}
\hline & \multicolumn{6}{|c|}{ Difference vs no cardiotoxicity } & \multirow{3}{*}{$\begin{array}{l}\text { P for } \\
\text { interaction }\end{array}$} \\
\hline & \multicolumn{3}{|l|}{ Visit 1} & \multicolumn{3}{|l|}{ Visit 2} & \\
\hline & Difference & $\begin{array}{l}95 \% \\
\mathrm{Cl}\end{array}$ & $\begin{array}{l}P \\
\text { value }\end{array}$ & Difference & $\begin{array}{l}95 \% \\
\mathrm{Cl}\end{array}$ & $\begin{array}{l}P \\
\text { value }\end{array}$ & \\
\hline GLS, \% & 0.57 & $\begin{array}{l}-0.32 \\
\text { to } \\
1.45\end{array}$ & 0.21 & 4.07 & $\begin{array}{l}3.15 \\
\text { to } \\
4.99\end{array}$ & $<.001$ & $<0.001$ \\
\hline \multicolumn{8}{|l|}{$\begin{array}{l}\text { 3D } \\
\text { Echocardiography }\end{array}$} \\
\hline LVEDVi, $\mathrm{mL} / \mathrm{m}^{2}$ & -3.07 & $\begin{array}{l}-9.03 \\
\text { to } \\
2.88\end{array}$ & 0.31 & 3.26 & $\begin{array}{l}-2.24 \\
\text { to } \\
8.77\end{array}$ & 0.25 & 0.06 \\
\hline LVESVi, $\mathrm{mL} / \mathrm{m}^{2}$ & -1.93 & $\begin{array}{l}-4.55 \\
\text { to } \\
0.70\end{array}$ & 0.15 & 1.91 & $\begin{array}{l}-1.40 \\
\text { to } \\
5.21\end{array}$ & 0.26 & 0.049 \\
\hline LVEF, \% & 1.73 & $\begin{array}{l}-1.31 \\
\text { to } \\
4.78\end{array}$ & 0.27 & -4.69 & $\begin{array}{l}-9.86 \\
\text { to } \\
0.47\end{array}$ & 0.08 & 0.001 \\
\hline \multicolumn{8}{|l|}{ Biomarkers $\left(\log _{2}\right)$} \\
\hline \multicolumn{8}{|l|}{$\begin{array}{l}\text { Cardiomyocyte } \\
\text { stress/damage }\end{array}$} \\
\hline NTproBNP, pg/mL & 0.49 & $\begin{array}{l}-0.02 \\
\text { to } \\
1.00\end{array}$ & 0.06 & 0.44 & $\begin{array}{l}-0.10 \\
\text { to } \\
0.99\end{array}$ & 0.11 & 0.53 \\
\hline hs-TnT, ng/L & -0.03 & $\begin{array}{l}-0.70 \\
\text { to } \\
0.64\end{array}$ & 0.93 & 0.13 & $\begin{array}{l}-0.32 \\
\text { to } \\
0.59\end{array}$ & 0.56 & 0.82 \\
\hline \multicolumn{8}{|l|}{ Myocardial stress } \\
\hline Galectin 3, ng/mL & 0.004 & $\begin{array}{l}-0.19 \\
\text { to } \\
0.20\end{array}$ & 0.97 & -0.03 & $\begin{array}{l}-0.31 \\
\text { to } \\
0.25\end{array}$ & 0.82 & 0.92 \\
\hline $\mathrm{sST} 2, \mathrm{ng} / \mathrm{mL}$ & 0.27 & $\begin{array}{l}-0.32 \\
\text { to } \\
0.85\end{array}$ & 0.37 & -0.06 & $\begin{array}{l}-0.35 \\
\text { to } \\
0.24\end{array}$ & 0.71 & 0.54 \\
\hline
\end{tabular}

Abbreviations as in Table 1. *Significant after Benjamini and Hochberg multiple-test correction (5\% FDR) in the biomarker analyses 


\begin{tabular}{|c|c|c|c|c|c|c|c|}
\hline & \multicolumn{6}{|c|}{ Difference vs no cardiotoxicity } & \multirow{3}{*}{$\begin{array}{l}\text { P for } \\
\text { interaction }\end{array}$} \\
\hline & \multicolumn{3}{|l|}{ Visit 1} & \multicolumn{3}{|l|}{ Visit 2} & \\
\hline & Difference & $\begin{array}{l}95 \% \\
\mathrm{Cl}\end{array}$ & $\begin{array}{l}P \\
\text { value }\end{array}$ & Difference & $\begin{array}{l}95 \% \\
\mathrm{Cl}\end{array}$ & $\begin{array}{l}P \\
\text { value }\end{array}$ & \\
\hline VCAM-1, ng/mL & 0.005 & $\begin{array}{l}-0.10 \\
\text { to } \\
0.11\end{array}$ & 0.93 & 0.10 & $\begin{array}{l}-0.10 \\
\text { to } \\
0.30\end{array}$ & 0.32 & 0.39 \\
\hline \multicolumn{8}{|l|}{ Myocardial fibrosis } \\
\hline $\mathrm{PICP}, \mathrm{ng} / \mathrm{mL}$ & -0.12 & $\begin{array}{l}-0.34 \\
\text { to } \\
0.09\end{array}$ & 0.26 & 0.57 & $\begin{array}{l}0.27 \\
\text { to } \\
0.87\end{array}$ & $<.001 *$ & $<0.001^{*}$ \\
\hline CITP, ng/mL & 0.10 & $\begin{array}{l}-0.22 \\
\text { to } \\
0.42\end{array}$ & 0.54 & 0.24 & $\begin{array}{l}-0.08 \\
\text { to } \\
0.57\end{array}$ & 0.14 & 0.45 \\
\hline CITP:MMP-1 ratio & -0.34 & $\begin{array}{l}-0.81 \\
\text { to } \\
0.13\end{array}$ & 0.15 & -0.08 & $\begin{array}{l}-0.65 \\
\text { to } \\
0.48\end{array}$ & 0.77 & 0.62 \\
\hline
\end{tabular}

Of the 14 patients with subclinical cardiotoxicity at visit 2, three patients presented a reduction of LVEF > $10 \%$ versus baseline to a value lower than $53 \%$ and 4 patients exhibited LVEF reductions $>15 \%$ as compared with baseline. Of interest, these patients exhibited higher PICP levels at visit 2 (mean [95\% Cl]: $175[103-208] \mathrm{ng} / \mathrm{mL})$ as compared with patients without cardiotoxicity $(86.5[70.2-113] \mathrm{ng} / \mathrm{mL})$ (Difference values $\left[\log _{2}\right]=0.66[95 \% \mathrm{Cl}: 0.24$ to 1.09$], P$ for interaction $=0.002$ ).

\section{Analyses of associations}

Univariable linear relationships between levels of the biomarkers that showed variations across visits and all echocardiographic parameters were evaluated in all patients (Supplemental Table S4). Of interest, NTproBNP, hs-TnT, VCAM-1 and PICP exhibited a direct association with a relative reduction of GLS along chemotherapy (Supplemental Table S4).

To identify factors independently associated with the relative reduction of GLS, we conducted multivariable linear mixed regression analyses including all characteristics associated with this echocardiographic parameter (defined as $P \leq 0.10$ in univariable analysis) as shown in Table 3 . The final model revealed that, along with NT-proBNP, a progressive increment in PICP levels is an independent significant predictor of the relative reduction of GLS over the course of chemotherapy (Fig. 2B, Table 3). 
Table 3

Univariable and multivariable linear mixed model analyses for the associations with global longitudinal strain

\begin{tabular}{|c|c|c|c|c|}
\hline & Univariable & & Multivariable & \\
\hline & Estimate $(95 \% \mathrm{Cl})$ & $\begin{array}{l}\mathrm{P} \\
\text { value }\end{array}$ & Estimate $(95 \% \mathrm{Cl})$ & $\begin{array}{l}P \\
\text { value }\end{array}$ \\
\hline Age, years & $0.02(-0.02$ to 0.06$)$ & 0.34 & & \\
\hline $\mathrm{BMI}, \mathrm{kg} / \mathrm{m}^{2}$ & 0.11 (0.02 to 0.19$)$ & 0.011 & $\begin{array}{l}0.04(-0.06 \text { to } \\
0.15)\end{array}$ & 0.38 \\
\hline Left breast, yes/no & $-0.17(-1.06$ to 0.73$)$ & 0.71 & & \\
\hline Ki67, \% & $-0.003(-0.02$ to 0.02$)$ & 0.76 & & \\
\hline ER and/or PR positive, yes/no & $-0.21(-1.28$ to 0.86$)$ & 0.70 & & \\
\hline TNM Stages & $-0.03(-0.26$ to 0.21$)$ & 0.83 & & \\
\hline \multicolumn{5}{|l|}{$\begin{array}{l}\text { ZMedian cumulative dose, } \\
\text { yes/no }\end{array}$} \\
\hline Epirubicin $\geq 377$ mg/m² & $-0.83(-1.69$ to 0.04$)$ & 0.061 & $\begin{array}{l}-0.30(-1.22 \text { to } \\
0.62)\end{array}$ & 0.52 \\
\hline $\begin{array}{l}\text { Cyclophosphamide } \geq \\
3820 \mathrm{mg} / \mathrm{m}^{2}\end{array}$ & 1.03 (0.18 to 1.89 ) & 0.017 & $\begin{array}{l}1.05(0.17 \text { to } \\
1.92)\end{array}$ & 0.020 \\
\hline Paclitaxel, yes/no & $-0.06(-1.24$ to 1.12$)$ & 0.92 & & \\
\hline \multicolumn{5}{|l|}{ Other treatments, yes/no } \\
\hline Carboplatin & $0.03(-0.89$ to 0.95$)$ & 0.95 & & \\
\hline Trastuzumab \pm Pertuzumab & $-0.27(-1.27$ to 0.73$)$ & 0.59 & & \\
\hline Surgery & $0.48(-0.35$ to 1.31$)$ & 0.26 & & \\
\hline Radiotherapy & $1.11(-0.02$ to 2.24$)$ & 0.054 & $\begin{array}{l}0.32(-0.93 \text { to } \\
1.57)\end{array}$ & 0.62 \\
\hline \multicolumn{5}{|l|}{ Comorbidities, yes/no } \\
\hline Hypertension & 1.27 (0.06 to 2.49$)$ & 0.040 & $\begin{array}{l}-0.11(-1.33 \text { to } \\
1.11)\end{array}$ & 0.86 \\
\hline Obesity & $0.98(-0.06$ to 2.02$)$ & 0.064 & & \\
\hline
\end{tabular}

BMI means body mass index; ER, estrogen receptor; PR, progesterone receptor; HER2, human epidermal growth factor receptor 2; eGFR, estimated glomerular filtration rate; AST, aspartate aminotransferase; ALT, alanine aminotransferase; GGT, gamma glutamyltransferase; ALP, alkaline phosphatase. Other abbreviations as in Table 1. 


\begin{tabular}{|c|c|c|c|c|}
\hline & Univariable & & Multivariable & \\
\hline Dyslipemia & 1.42 (0.14 to 2.71$)$ & 0.030 & $\begin{array}{l}0.33(-0.81 \text { to } \\
1.47)\end{array}$ & 0.57 \\
\hline Current smoking & $0.57(-0.85$ to 1.99$)$ & 0.43 & & \\
\hline \multicolumn{5}{|l|}{ Hematological parameters } \\
\hline Hemoglobin, g/dL & $-0.11(-0.24$ to 0.03$)$ & 0.11 & & \\
\hline Hematocrit, \% & $-0.05(-0.10$ to 0.008$)$ & 0.022 & $\begin{array}{l}0.01(-0.06 \text { to } \\
0.07)\end{array}$ & 0.90 \\
\hline Platelets, $10^{9} / \mathrm{L}$ & $\begin{array}{l}-0.001(-0.005 \text { to } \\
0.002)\end{array}$ & 0.42 & & \\
\hline Leukocytes $\left(\log _{2}\right), 10^{9} / \mathrm{mL}$ & $-0.41(-0.97$ to 0.14$)$ & 0.14 & & \\
\hline Neutrophils, \% & $0.007(-0.01$ to 0.02$)$ & 0.40 & & \\
\hline Lymphocytes, \% & $-0.02(-0.04$ to 0.002$)$ & 0.09 & $\begin{array}{l}-0.01(-0.04 \text { to } \\
0.02)\end{array}$ & 0.45 \\
\hline Monocytes, \% & $0.02(-0.03$ to 0.07$)$ & 0.47 & & \\
\hline \multicolumn{5}{|l|}{ Renal function parameters } \\
\hline eGFR, mL/min/1.73 $\mathrm{m}^{2}$ & $-0.01(-0.03$ to 0.01$)$ & 0.14 & & \\
\hline \multicolumn{5}{|l|}{ Liver function parameters } \\
\hline AST $\left(\log _{2}\right), I U / L$ & $0.18(-0.46$ to 0.81$)$ & 0.59 & & \\
\hline ALT $\left(\log _{2}\right), I U / L$ & $0.11(-0.27$ to 0.49$)$ & 0.58 & & \\
\hline GGT $\left(\log _{2}\right), I U / L$ & $-0.02(-0.24$ to 0.20$)$ & 0.86 & & \\
\hline ALP $\left(\log _{2}\right), I U / L$ & 0.66 (0.12 to 1.20$)$ & 0.017 & $\begin{array}{l}0.10(-0.67 \text { to } \\
0.86)\end{array}$ & 0.80 \\
\hline Baseline GLS $\geq-17 \%$ & 3.59 (2.98 to 4.19 ) & $<.001$ & $\begin{array}{l}2.98 \text { ( } 1.33 \text { to } \\
4.62)\end{array}$ & <. 001 \\
\hline \multicolumn{5}{|l|}{ Biomarkers } \\
\hline NT-proBNP $\left(\log _{2}\right), p g / m L$ & 0.35 (0.10 to 0.60$)$ & 0.006 & $\begin{array}{l}0.31 \text { ( } 0.006 \text { to } \\
0.61 \text { ) }\end{array}$ & 0.046 \\
\hline
\end{tabular}

$\mathrm{BMI}$ means body mass index; $\mathrm{ER}$, estrogen receptor; $\mathrm{PR}$, progesterone receptor; $\mathrm{HER} 2$, human epidermal growth factor receptor 2; eGFR, estimated glomerular filtration rate; AST, aspartate aminotransferase; ALT, alanine aminotransferase; GGT, gamma glutamyltransferase; ALP, alkaline phosphatase. Other abbreviations as in Table 1. 


\begin{tabular}{|c|c|c|c|c|}
\hline & \multicolumn{2}{|l|}{ Univariable } & \multicolumn{2}{|l|}{ Multivariable } \\
\hline hs-TnT $\left(\log _{2}\right), \mathrm{ng} / \mathrm{L}$ & 0.34 (0.05 to 0.64$)$ & 0.024 & $\begin{array}{l}0.21(-0.15 \text { to } \\
0.56)\end{array}$ & 0.26 \\
\hline VCAM (log2), ng/mL & 1.06 (0.20 to 1.92$)$ & 0.016 & $\begin{array}{l}0.57(-0.39 \text { to } \\
1.52)\end{array}$ & 0.24 \\
\hline PICP $\left(\log _{2}\right), n g / m L$ & 0.94 (0.43 to 1.45$)$ & $<.001$ & $\begin{array}{l}0.97 \text { ( } 0.43 \text { to } \\
1.51)\end{array}$ & $\dot{0} .001$ \\
\hline \multicolumn{5}{|c|}{$\begin{array}{l}\text { BMI means body mass index; ER, estrogen receptor; PR, progesterone receptor; HER2, human } \\
\text { epidermal growth factor receptor 2; eGFR, estimated glomerular filtration rate; AST, aspartate } \\
\text { aminotransferase; ALT, alanine aminotransferase; GGT, gamma glutamyltransferase; ALP, alkaline } \\
\text { phosphatase. Other abbreviations as in Table 1. }\end{array}$} \\
\hline
\end{tabular}

The associations of biomarker values at baseline or interval changes across visits with subclinical cardiotoxicity at visit 2 were estimated by univariable logistic regression analyses (Table S5). As shown in the table, only the increments in PICP between baseline and visit 2 and between visit 1 and visit 2 were significantly associated with subclinical cardiotoxicity (Table S5). Specifically, there was more than a 3fold increase in the risk of subclinical cardiotoxicity for each increase in 1 SD of PICP change at visit 2 versus baseline (which corresponded to a PICP increment of 58\%) or versus visit 1 (which corresponded to a PICP increment of 65\%). Of note, the associations between PICP changes (per 1SD) and the risk of subclinical cardiotoxicity were independent of the declines at visit 1 in hemoglobin (visit 2 vs baseline: $\mathrm{OR}=4.42[95 \% \mathrm{Cl}: 1.70-11.5], \mathrm{P}=0.002$; visit 2 vs visit $1: \mathrm{OR}=5.14[95 \% \mathrm{Cl}: 2.02-13.1], \mathrm{P}=0.001)$ and in the hematocrit percentage (visit 2 vs baseline: $O R=4.55[95 \% \mathrm{Cl}: 1.64-12.6], P=0.004$; visit 2 vs visit 1 : $\mathrm{OR}=5.52[95 \% \mathrm{Cl}: 1.99-15.3], \mathrm{P}=0.001)$, as the only parameters exhibiting significant interactions with subclinical cardiotoxicity (Table S3).

ROC analyses showed significant diagnostic performances for PICP increments at visit 2 vs baseline or a visit 2 vs visit 1 to predict subclinical cardiotoxicity (visit 2 vs baseline: AUC $=0.800$ [95\%Cl: $0.639-0.960$ ], $P=0.001$; visit 2 vs visit 1 : AUC $=0.819$ [95\%Cl: 0.687-0.951], $P<0.001$ ) (Figure S1), with cut-off values of $65.3 \%$ (79\% sensitivity, $82 \%$ specificity) and of $105 \%$ ( $64 \%$ sensitivity, $87 \%$ specificity) respectively. In addition, PICP increments at visit 2 vs baseline predicted cardiotoxicity as assessed by a decrease in LVEF (AUC $=0.805$ [95\%Cl: 0.586-1.0], $P=0.008$ ).

\section{Study 2: Patients with HF}

\section{Characteristics of patients at baseline}

As shown in supplemental Table S6, all HF etiology groups were matched for age, sex, body mass index, potassium levels, eGFR, NYHA class, HF duration, number of previous hospitalizations, LVEF, and NTproBNP levels. ACC-HF patients exhibited lower prevalence of atrial fibrillation as compared with HHD and VHD groups, and lower prevalence of hypercholesterolemia and frequency of treatment with statins and nitrates compared with patients with IHD. As for the remaining clinical characteristics, ACC-HF 
patients were matched with all groups (Supplemental Table S6). Of interest, PICP levels were similar in all HF etiologies (Supplemental Table S6).

\section{Analysis of associations}

Univariable linear relationships showed that NT-proBNP and PICP exhibited inverse associations with LVEF in ACC-HF patients (Table 4). Of interest, PICP association with LVEF in these patients was independent of NT-proBNP levels (Table 4). In addition, whereas NT-proBNP was inversely associated with LVEF also in HF patients of DCM and HHD origin, no other association was found between PICP and LVEF in the remaining HF etiologies (Table 4). 
Table 4

Associations between NT-proBNP, PICP and LVEF

\section{LVEF, \%}

$\begin{array}{llll}\text { Estimate } & 95 \% \mathrm{Cl} & \mathrm{R}^{2} & \text { P value }\end{array}$

Independent variables

NT-proBNP $\left(\log _{2}\right), \mathrm{ng} / \mathrm{mL}$

\section{Etiologies}

\begin{tabular}{lllll} 
IHD & -0.70 & -2.39 to 1.00 & 0.01 & 0.41 \\
DCM & -1.05 & -2.09 to -0.004 & 0.05 & 0.049 \\
\hline HHD & -3.48 & -5.84 to -1.12 & 0.17 & 0.005 \\
\hline VHD & -1.05 & -3.03 to 0.92 & 0.03 & 0.29 \\
\hline Others & 0.03 & -1.80 to 1.85 & $<0.001$ & 0.98 \\
\hline ACC-HF & -2.80 & -4.44 to -1.17 & 0.26 & 0.001
\end{tabular}

$\operatorname{PICP}\left(\log _{2}\right), \mathrm{ng} / \mathrm{mL}$

\section{Etiologies}

\begin{tabular}{|lllll|}
\hline IHD & -0.42 & -4.49 to 3.65 & $<0.01$ & 0.84 \\
\hline DCM & 1.16 & -3.45 to 5.77 & $<0.01$ & 0.62 \\
\hline HHD & -0.14 & -10.7 to 10.4 & $<0.01$ & 0.98 \\
\hline VHD & -3.41 & -10.2 to 3.42 & 0.02 & 0.32 \\
\hline Others & 1.77 & -4.39 to 7.92 & $<0.01$ & 0.57 \\
\hline ACC-HF & -10.5 & -17.4 to -3.66 & 0.22 & $0.004^{*}$ \\
\hline
\end{tabular}

NT-proBNP means N-terminal pro-B-type natriuretic peptide; PICP, procollagen type I C-terminal propeptide; LVEF, left ventricular ejection fraction; IHD, ischemic heart disease; DCM, diabetic cardiomyopathy; HHD, hypertensive heart disease; VHD, valvular heart disease; ACC-HF, anthracyclinebased chemotherapy-induced heart failure.

*P $=0.022$ after adjustment by NT-proBNP (Estimate $[95 \% \mathrm{Cl}]=-7.77[-14.4$ to -1.18$]$; model $\mathrm{R}^{2}=0.36$ )

\section{Analysis of LVEF longitudinal changes over one year}

LVEF was measured at 12 months after recruitment in 33 ACC-HF patients. These patients were categorized according to baseline PICP tertiles in patients with low (1st tertile: $<100 \mathrm{ng} / \mathrm{mL}, \mathrm{n}=11$ ), medium (2nd tertile: $100-129 \mathrm{ng} / \mathrm{mL}, \mathrm{n}=11$ ) and high (3rd tertile: $>129 \mathrm{ng} / \mathrm{mL}, \mathrm{n}=11$ ) PICP levels. As 
shown in Fig. 3, baseline LVEF-adjusted analyses revealed that, after one year, LVEF improved in patients with low or medium PICP but remained unchanged in those with high PICP levels at baseline.

\section{Study 3: In vitro findings}

In a first step, dose-response curves were performed for doxorubicin, cyclophosphamide, paclitaxel and trastuzumab in HDFs. Concentrations with significant submaximal effects on cell viability and procollagen type-I mRNA expression, and two lower doses, were chosen for each agent to be tested in HCFs (Supplemental Figure S2). As shown in supplemental Table S7, all agents decreased the number of cells and increased SMA mRNA expression as compared with control in HCFs. In addition, doxorubicin, cyclophosphamide and trastuzumab, but not paclitaxel, increased the expression of procollagen type-I mRNA as compared with control (Fig. 4A-C). Moreover, these three compounds increased the expression of PCP and increased the extracellular protein levels of collagen and PICP (Fig. 4D-F), as well as LOX activity (Supplemental Table S7). Finally, doxorubicin and cyclophosphamide increased the expression of PCPE, and cyclophosphamide and trastuzumab increased LOX mRNA expression, as compared with control (Supplemental Table S7).

\section{Discussion}

The major findings of this study are the following: 1) In patients with breast cancer there was a relative GLS reduction accompanied by increments in serum NT-proBNP, hs-TnT, VCAM- 1 and PICP after 6 months-chemotherapy, without changes in the remaining biomarkers; 2) PICP increment after chemotherapy was more pronounced in the subset of patients who developed subclinical cardiotoxicity; 3) Levels of PICP were directly and independently associated with the relative GLS reduction over the course of chemotherapy; 4) Levels of PICP were inversely associated with LVEF in ACC-HF patients; 5) High levels of PICP at baseline were associated with lack of LVEF improvement after 12 months in ACCHF patients; and 6) the cardiotoxic agents doxorubicin, cyclophosphamide and trastuzumab stimulated the differentiation of HCFs to a myofibroblast collagen-synthesizing phenotype. To our knowledge, this is the first study evaluating the effects of cancer chemotherapy on myocardial collagen, as assessed noninvasively by using circulating biomarkers associated with histologically-proven MIF. In addition, to the best of our knowledge, this is the first time that the effects of chemotherapy agents on collagen metabolism have been evaluated in HCFs.

It has been widely demonstrated that NT-proBNP and hs-TnT levels increase during cancer therapy, although their utility for cardiotoxicity prediction has been recently questioned [19, 23-25]. In this study, we have reported chemotherapy-induced increments in these biomarkers associated with a reduction of LV contractility, although the association shown by hs-TnT was not independent of confounding factors. On the other hand, conflicting results have been shown regarding longitudinal changes in circulating VCAM-1, galectin-3 and SST2 during cancer treatment $[23,25,26]$, thus further studies are necessary to confirm the influence of oncologic therapy on the serum levels of these proteins. The current study is the first to report that anthracycline-based-chemotherapy for breast cancer increases the circulating levels of 
a biomarker that reflects increased collagen deposition in the myocardium [16], being this increase particularly evident in patients developing subclinical cardiotoxicity. In addition, we have found an association between biomarker-assessed myocardial collagen content and a reduction of LV contractility along chemotherapy, independently of relevant clinical factors including chemotherapy cumulative doses and biomarkers of cardiomyocyte damage. Importantly, this association between biomarker-assessed MIF and decreased LV contractility was further confirm in patients with ACC-HF. Even more, longitudinal pilot observations in these patients suggest that the degree of MIF at baseline may influence evolution of LV function over time.

These findings reinforce the notion that, not only the cardiomyocyte injury, but also the presence of MIF seems to be relevant for the impairment of LV contractile function in cancer patients treated with anthracycline-based chemotherapy [7]. Mechanistically, these effects combined may result in larger accumulation of collagen encircling cardiac muscle with reduced functionality, further restricting the stretching of muscle fibers and impairing the direct cell-to-cell communication necessary for synchronous activation of cardiomyocytes [27]. In this regard, several studies demonstrate a detrimental effect of MIF on the deformation of the LV wall (i.e. reduced GLS), in experimental models [28] and in patients with different cardiomyopathies [29-32]. Of notice, the PICP levels here observed in breast cancer patients with cardiotoxicity and in patients with ACC-HF were similar to those found in hypertensive heart failure patients with severe MIF [33]. It is also important to acknowledge the potential influence of a systemic reparative response after ACC treatment on the levels of serum PICP, with activation of fibrotic processes in organs other than the heart. In this regard, it has been shown that anti-cancer therapies may cause arterial stiffness, with increased collagen production suggested as a potential mechanism, among others, underlying this vascular alteration $[34,35]$. Since arterial stiffness contributes to LVD, we cannot discard that the association found between PICP with LVD in ACC-treated patients is reflecting the combined interaction of cardiac and vascular fibrosis.

Although several studies have reported profibrotic effects of anthracyclines, cyclophosphamide, paclitaxel and trastuzumab in the myocardium of experimental models of cardiotoxicity [8-14], and in rodent cardiac fibroblasts $[9,11]$, the role of these agents in HCFs has not been characterized. In this regard, we describe that doxorubicin, cyclophosphamide and trastuzumab stimulated the differentiation to a myofibroblast collagen-synthesizing phenotype, including enhanced presence of PICP in the extracellular medium. Therefore, we may speculate that cardiotoxic agents used to treat breast cancer may directly stimulate HCFs differentiation and collagen fiber synthesis and deposition. In this regard, it has been suggested that the anthracycline profibrotic effects are mediated through substance P, ROS, STAT3 and atypical $G$ protein $G \beta_{5}$-related mechanisms $[9,11]$. In addition, cyclophosphamide has been shown to induce human lung fibroblasts premature senescence by activating the MAP kinase signaling pathway [36]. Whether these pathways are involved in the pro-fibrotic actions exerted by these agents in HCFs require further studies.

Some limitations of the present study must be acknowledged. First, small sample size may have constrained statistical power to detect differences in the different biomarkers assessed in patients with 
breast cancer, and preclude from adequately assess the impact of potential confounders in the association and longitudinal analyses in ACC-HF patients. Second, there is lack of follow-up information beyond the considered treatment period in patients with breast cancer, but long-term follow-up is planned and ongoing. Third, serum samples after 1-year follow-up were not available to measure PICP in ACC-HF patients. Fourth, our data cannot be extrapolated to oncologic patients treated with other anti-cancer drugs different from those evaluated in this study. Fifth, because they are descriptive in nature, the associations found between PICP and cardiotoxicity do not establish causality. Finally, we cannot discard extra-cardiac sources of PICP. In this regard, determining the extracellular volume fraction in the myocardium by means of cardiac magnetic resonance could have enriched the description of the influence of myocardial fibrosis on PICP serum levels in ACC-treated patients.

In summary, this study shows for the first time that the circulating biomarker of myocardial collagen typeI deposition, PICP, is elevated in the blood of women receiving breast cancer anthracycline-based chemotherapy. In addition, we report that PICP increment is particularly pronounced in those patients with signs of early LV dysfunction, being the levels of this peptide directly and independently associated with a reduction of LV contractility along chemotherapy. Moreover, we confirm the association of PICP with LV contractile dysfunction in patients with ACC-HF, with high levels of this peptide associated with a lack of improvement in LV contractility over time. Finally, we show for the first time that anthracyclines, cyclophosphamide and trastuzumab exert profibrotic actions, particularly increasing collagen type-I synthesis, in HCFs. These results provide additional evidence for MIF as a cardiotoxic side-effect of anthracycline-based breast cancer treatment, and allow us to speculate that this lesion may be a pathophysiological mechanism underlying LVD in these patients. Finally, these preliminary findings should be considered in the context of a pilot hypothesis-generating study supporting the need of further studies designed to evaluate the prognostic potential of PICP, either by itself or combined with other biomarkers of myocardial remodeling, to monitor cardiotoxicity in larger cohorts of patients under chemotherapy.

\section{Declarations}

Ethical approval: All procedures performed in studies involving human participants were in accordance with the ethical standards of the Clinical Investigation Ethics Committees of the University of Navarra and of the Hospital Universitari Germans Trias i Pujol. All study procedures were in accordance with the ethical standards outlined in the Helsinki Declaration of 1975 as revised in 1983.

Consent for publication: Not applicable

Data availability: The data underlying this article will be shared on reasonable request to the corresponding authors.

Conflict of interest: AB-G has received honoraria for lectures and advisory boards for Novartis, Vifor, Boehringer Ingelheim, Roche Diagnostics and Critical Diagnostics. The remaining authors have nothing to disclose.

Page 22/30 
Funding: This work was supported by the Ministry of Economy and Competitiveness, Spain (Instituto de Salud Carlos III: CB16/11/00483, PI17/01999 and PI18/01469 co-financed by FEDER funds), the Ministerio de Educación y Ciencia (SAF2017-84324-C2-1-R to A.B-G.), CIBER Cardiovascular (CB16/11/00403 to A.B-G.), and AdvanceCat (2014-2020 to A.B-G.).

Author contributions: A.F., M.S. and J.M.A. co-designed the study, made substantial contributions to the acquisition of data and revised the manuscript critically for important intellectual content; A.F. and A.D. did the echocardiographic analyses; J.L., G.C., B.L., J.M.L.P., G.R., made substantial contributions to the acquisition of data and revised the manuscript critically for important intellectual content; S.R. analysed and interpreted the data, and drafted the work; J.D., A.G., A.B-G., and S.R. co-designed the study, acquired funding and provided resources, edited the manuscript and revised the manuscript critically for important intellectual content. All Authors have given their final approval of the version to be submitted.

Acknowledgements: The authors thank Sonia Martínez and Ana Igea for their valuable technical assistance, the patients for their participation and the Biobank of the University of Navarra for its collaboration.

\section{References}

1. Armenian SH, Lacchetti C, Barac A, Carver J, Constine LS, Denduluri N, et al. Prevention and Monitoring of Cardiac Dysfunction in Survivors of Adult Cancers: American Society of Clinical Oncology Clinical Practice Guideline. J Clin Oncol. 2017;35:893-911. https://doi.org/10.1200/JC0.2016.70.5400.

2. Bradshaw PT, Stevens J, Khankari N, Teitelbaum SL, Neugut Al, Gammon MD. Cardiovascular disease mortality among breast cancer survivors. Epidemiology. 2016;27:6-13. https://doi.org/10.1097/EDE.0000000000000394.

3. Gernaat SAM, Ho PJ, Rijnberg N, Emaus MJ, Baak LM, Hartman M, et al. (2017) Risk of death from cardiovascular disease following breast cancer: a systematic review. Breast Cancer Res Treat. 2017;164:537-555. https://doi.org/10.1007/s10549-017-4282-9.

4. Patnaik JL, Byers T, DiGuiseppi C, Dabelea D, Denberg TD. Cardiovascular disease competes with breast cancer as the leading cause of death for older females diagnosed with breast cancer: a retrospective cohort study. Breast Cancer Res. 2011;13:R64. https://doi.org/10.1186/bcr2901.

5. Anker MS, Hadzibegovic S, Lena A, Belenkov Y, Bergler-Klein J, de Boer RA, et al. Recent advances in cardio-oncology: a report from the 'Heart Failure Association 2019 and World Congress on Acute Heart Failure 2019. ESC Heart Fail. 2019;6:1140-8. https://doi.org/10.1002/ehf2.12551.

6. Ausoni S, Calamelli S, Saccà S, Azzarello G. How progressive cancer endangers the heart: an intriguing and underestimated problem. Cancer Metastasis Rev. 2020;39:535-52. https://doi.org/10.1007/s10555-020-09869-8.

7. Meléndez GC, Hundley WG. Is Myocardial Fibrosis a New Frontier for Discovery in Cardiotoxicity Related to the Administration of Anthracyclines? Circ Cardiovasc Imaging. 2016;9:e005797. 
https://doi.org/10.1161/CIRCIMAGING.116.005797.

8. Gyöngyösi M, Lukovic D, Zlabinger K, Spannbauer A, Gugerell A, Pavo N, et al. Liposomal doxorubicin attenuates cardiotoxicity via induction of interferon-related DNA damage resistance. Cardiovasc Res. 2020;116:970-82. https://doi.org/10.1093/cvr/cvz192.

9. Levick SP, Soto-Pantoja DR, Bi J, Hundley WG, Widiapradja A, Manteufel EJ, et al. DoxorubicinInduced Myocardial Fibrosis Involves the Neurokinin-1 Receptor and Direct Effects on Cardiac Fibroblasts. Heart Lung Circ. 2019;28:1598-605. https://doi.org/10.1016/j.hlc.2018.08.003.

10. Russo M, Guida F, Paparo L, Trinchese G, Aitoro R, Avagliano C, et al. The novel butyrate derivative phenylalanine-butyramide protects from doxorubicin-induced cardiotoxicity. Eur J Heart Fail. 2019;21:519-28. https://doi.org/10.1002/ejhf.1439.

11. Chakraborti S, Pramanick A, Saha S, Roy SS, Chaudhuri AR, Das M, et al. Atypical G Protein $\beta 5$ Promotes Cardiac Oxidative Stress, Apoptosis, and Fibrotic Remodeling in Response to Multiple Cancer Chemotherapeutics. Cancer Res. 2018;78:528-41. https://doi.org/10.1158/0008-5472.CAN17-1280.

12. Iqubal A, Sharma S, Ansari MA, Najmi AK, Syed MA, Ali J, et al. Nerolidol attenuates cyclophosphamide-induced cardiac inflammation, apoptosis and fibrosis in Swiss Albino mice. Eur J Pharmacol. 2019;863:172666. https://doi.org/10.1016/j.ejphar.2019.172666.

13. Liu Y, Tan D, Shi L, Liu X, Zhang Y, Tong C, et al. Blueberry Anthocyanins-Enriched Extracts Attenuate Cyclophosphamide-Induced Cardiac Injury. PLoS One. 2015;10:e0127813. https://doi.org/10.1371/journal.pone.0127813.

14. Coppola C, Riccio G, Barbieri A, Monti MG, Piscopo G, Rea D, et al. Antineoplastic-related cardiotoxicity, morphofunctional aspects in a murine model: contribution of the new tool 2D-speckle tracking. Onco Targets Ther. 2016;9:6785-94. https://doi.org/10.2147/OTT.S106528.

15. González A, Schelbert EB, Díez J, Butler J. Myocardial Interstitial Fibrosis in Heart Failure: Biological and Translational Perspectives. J Am Coll Cardiol. 2018;71:1696-706. https://doi.org/10.1016/j.jacc.2018.02.021.

16. López B, Querejeta R, González A, Larman M, Díez J. Collagen cross-linking but not collagen amount associates with elevated filling pressures in hypertensive patients with stage $\mathrm{C}$ heart failure: potential role of lysyl oxidase. Hypertension. 2012;60:677-83.

https://doi.org/10.1161/HYPERTENSIONAHA.112.196113.

17. López B, Ravassa S, González A, Zubillaga E, Bonavila C, Bergés M, et al. Myocardial collagen crosslinking is associated with heart failure hospitalization in patients with hypertensive heart failure. $J$ Am Coll Cardiol. 2016;67:251-60. https://doi.org/10.1016/j.jacc.2015.10.063.

18. Zamorano JL, Lancellotti P, Rodriguez Muñoz D, Aboyans V, Asteggiano R, Galderisi M, et al. ESC Scientific Document Group. 2016 ESC Position Paper on cancer treatments and cardiovascular toxicity developed under the auspices of the ESC Committee for Practice Guidelines: The Task Force for cancer treatments and cardiovascular toxicity of the European Society of Cardiology (ESC). Eur. Heart. J. 2016;37:2768-2801. https://doi.org/10.1093/eurheartj/ehw211. 
19. Goel S, Liu J, Guo H, Barry W, Bell R, Murray B, et al. Decline in Left Ventricular Ejection Fraction Following Anthracyclines Predicts Trastuzumab Cardiotoxicity. JACC Heart Fail. 2019;7:795-804. https://doi.org/10.1016/j.jchf.2019.04.014.

20. Lupón J, Gaggin HK, de Antonio M, Domingo M, Galán A, Zamora E, et al. Biomarker-assist score for reverse remodeling prediction in heart failure: The ST2-R2 score. Int J Cardiol. 2015;184:37-43. https://doi.org/10.1016/j.ijcard.2015.02.019.

21. López B, González A, Querejeta R, Larman M, Rábago G, Díez J. Association of cardiotrophin-1 with myocardial fibrosis in hypertensive patients with heart failure. Hypertension. 2014;63:483-9. https://doi.org/10.1161/HYPERTENSIONAHA.113.02654.

22. López B, González A, Lindner D, Westermann D, Ravassa S, Beaumont J, et al. Osteopontin-mediated myocardial fibrosis in heart failure: a role for lysyl oxidase? Cardiovasc Res. 2013;99:111-20. https://doi.org/10.1093/cvr/cvt100.

23. Tan LL, Lyon AR. Role of Biomarkers in Prediction of Cardiotoxicity During Cancer Treatment. Curr Treat Options Cardiovasc Med. 2018;20:55. https://doi.org/10.1007/s11936-018-0641-z.

24. Levis BE, Binkley PF, Shapiro CL. Cardiotoxic effects of anthracycline-based therapy: what is the evidence and what are the potential harms? Lancet Oncol. 2017;18:e445-56. https://doi.org/10.1016/S1470-2045(17)30535-1.

25. Gulati G, Heck SL, Røsjø H, Ree AH, Hoffmann P, Hagve TA, et al. Neurohormonal Blockade and Circulating Cardiovascular Biomarkers During Anthracycline Therapy in Breast Cancer Patients: Results From the PRADA (Prevention of Cardiac Dysfunction During Adjuvant Breast Cancer Therapy) Study. J Am Heart Assoc. 2017;6:e006513. https://doi.org/10.1161/JAHA.117.006513.

26. Kirwan CC, McCollum CN, McDowell G, Byrne GJ. Investigation of proposed mechanisms of chemotherapy-induced venous thromboembolism: endothelial cell activation and procoagulant release due to apoptosis. Clin Appl Thromb Hemost. 2015;21:420-7. https://doi.org/10.1177/1076029615575071.

27. Díez J, González A, Kovacic JC. Myocardial Interstitial Fibrosis in Nonischemic Heart Disease, Part 3/4: JACC Focus Seminar. J Am Coll Cardiol. 2020;75:2204-18. https://doi.org/10.1016/j.jacc.2020.03.019.

28. Leader CJ, Moharram M, Coffey S, Sammut IA, Wilkins GW, Walker RJ. Myocardial global longitudinal strain: An early indicator of cardiac interstitial fibrosis modified by spironolactone, in a unique hypertensive rat model. PLoS One. 2019;14:e0220837. https://doi.org/10.1371/journal.pone.0220837.

29. Park SJ, Cho SW, Kim SM, Ahn J, Carriere K, Jeong DS, et al. Assessment of Myocardial Fibrosis Using Multimodality Imaging in Severe Aortic Stenosis: Comparison With Histologic Fibrosis. JACC Cardiovasc Imaging. 2019;12:109-19. https://doi.org/10.1016/j.jcmg.2018.05.028.

30. Slimani A, Melchior J, de Meester C, Pierard S, Roy C, Amzulescu M, et al. Relative Contribution of Afterload and Interstitial Fibrosis to Myocardial Function in Severe Aortic Stenosis. JACC Cardiovasc Imaging. 2020;13:589-600. https://doi.org/10.1016/j.jcmg.2019.05.020. 
31. Fabiani I, Scatena C, Mazzanti CM, Conte L, Pugliese NR, Franceschi S, et al. Micro-RNA-21 (biomarker) and global longitudinal strain (functional marker) in detection of myocardial fibrotic burden in severe aortic valve stenosis: a pilot study. J Transl Med. 2016;14:248. https://doi.org/10.1186/s12967-016-1011-9.

32. Cameli M, Mondillo S, Righini FM, Lisi M, Dokollari A, Lindqvist P, et al. Left Ventricular Deformation and Myocardial Fibrosis in Patients With Advanced Heart Failure Requiring Transplantation. J Card Fail. 2016;22:901-7. https://doi.org/10.1016/j.cardfail.2016.02.012.

33. Ravassa S, López B, Querejeta R, Echegaray K, San José G, Moreno MU, et al. Phenotyping of myocardial fibrosis in hypertensive patients with heart failure. Influence on clinical outcome. $J$ Hypertens. 2017;35:853-61. https://doi.org/10.1097/HJH.0000000000001258.

34. Parr SK, Liang J, Schadler KL, Gilchrist SC, Steele CC. A de CJ. Anticancer Therapy-Related Increases in Arterial Stiffness: A Systematic Review and Meta-Analysis. J Am Heart Assoc. 2020;9:e015598. https://doi.org/10.1161/JAHA.119.015598.

35. Solomou E, Aznaouridis K, Masoura C, Cutajar I, Toutouzas K, Vlachopoulos C, Tousoulis D. Aortic wall stiffness as a side-effect of anti-cancer medication. Expert Rev Cardiovasc Ther. 2019;17:7919. https://doi.org/10.1080/14779072.2019.1691528.

36. Palaniyappan A. Cyclophosphamide induces premature senescence in normal human fibroblasts by activating MAP kinases. Biogerontology. 2009;10:677-82. https://doi.org/10.1007/s10522-0099215-5.

\section{Figures}




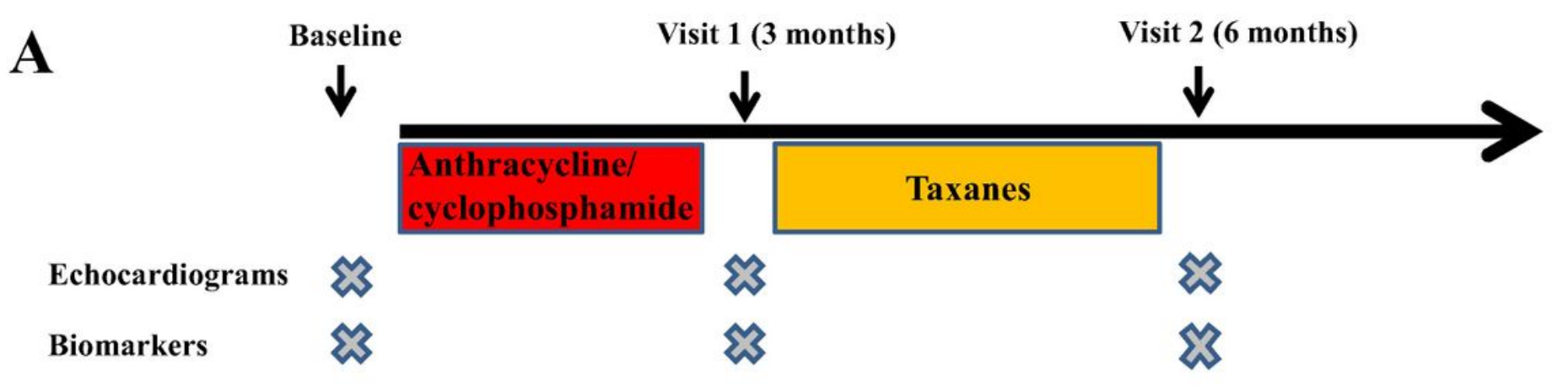

\section{B}

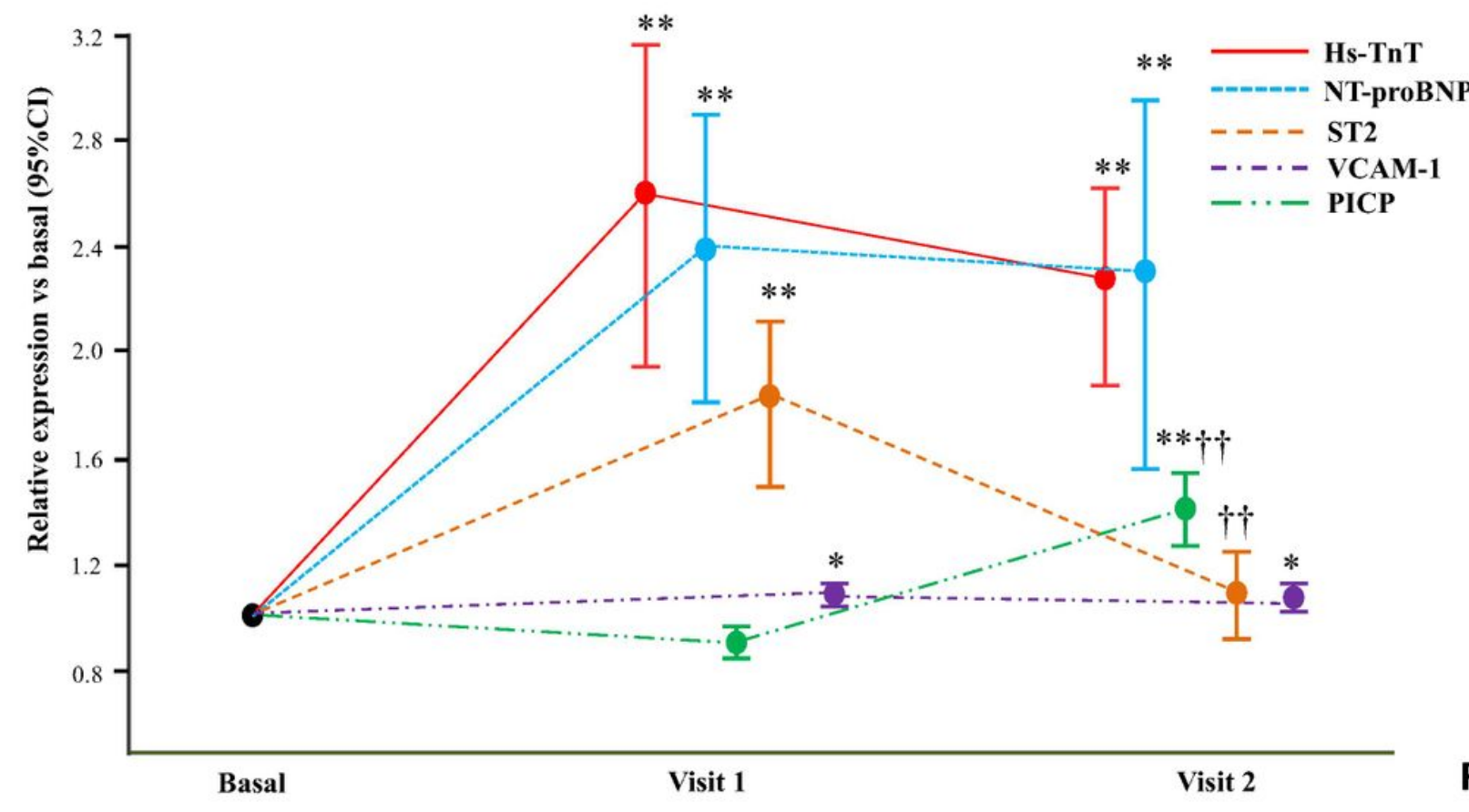

Fig 1

\section{Figure 1}

Study protocol and relative changes in biomarkers in patients with breast cancer. A, The diagram depicts the study protocol. Patients with breast cancer were studied before chemotherapy, after treatment with epirubicin/cyclophosphamide at 3 months (visit 1) and after treatment with taxanes (with or without antiHER2 therapy) at 6 months (visit 2). The echocardiograms and biomarkers were evaluated at baseline, at visit 1 and at visit 2. B, Relative changes in biomarker levels with respect to baseline in patients with breast cancer at visit 1 and visit 2 . Data are expressed as mean values and $95 \%$ confidence interval at visit 1 and visit $2 .{ }^{*} P<0.01$ vs baseline, ${ }^{*} P<0.001$ vs baseline, $+P<0.05$ vs visit $1,++P<0.001$ vs visit 1 (Linear mixed regression adjusted by baseline biomarker levels, followed by pairwise contrast tests with a Bonferroni's-corrected $p$ value and Benjamini and Hochberg multiple test correction). NT-proBNP, aminoterminal pro-brain natriuretic peptide; hs-TnT, high sensitivity troponin T; SST2, soluble suppression of tumourigenicity-2; VCAM-1, vascular cell adhesion molecule-1; PICP, procollagen type I C-terminal propeptide. 

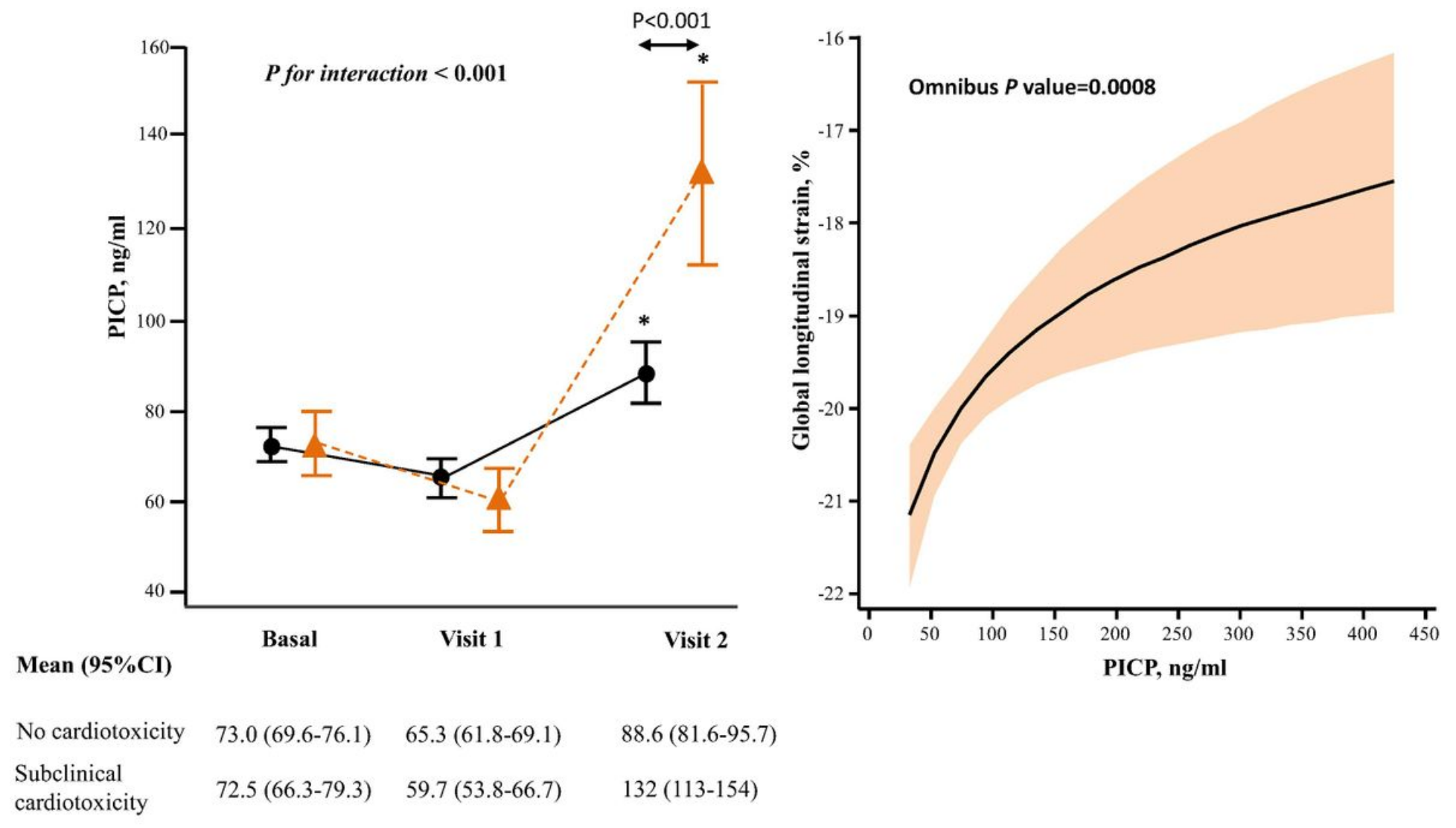

No cardiotoxicity $\quad 73.0(69.6-76.1) \quad 65.3(61.8-69.1) \quad 88.6(81.6-95.7)$

$\begin{array}{lll}\begin{array}{l}\text { Subclinical } \\ \text { cardiotoxicity }\end{array} \quad 72.5(66.3-79.3) & 59.7(53.8-66.7) & 132(113-154)\end{array}$

\section{Figure 2}

Procollagen type I C-terminal propeptide (PICP) levels and early left ventricular dysfunction in patients with breast cancer. A, PICP circulating levels at baseline and after treatment with epirubicine/cyclophosphamide at 3 months (visit 1) followed by treatment with taxanes (with or without anti-HER2 therapy) at 6 months (visit 2), according to absence or presence of subclinical cardiotoxicity at visit 2. Data are expressed as the predicted mean values (estimated marginal means of visits by group) and $95 \%$ confidence interval $(\mathrm{Cl})$ at baseline, visit 1 and visit 2 after linear mixed regression analysis with PICP as the dependent variable, and subclinical cardiotoxicity at visit 2, visit, their interaction term, and PICP baseline values as fixed effects. ${ }^{*} P<0.001$ vs baseline and visit 1 . B. Association of PICP with global longitudinal strain (GLS) (solid black line) and 95\% confidence intervals (color shade) along treatment after multivariable linear mixed regression with adjustment for body mass index, cyclophosphamide and epirubicine doses, radiotherapy schedule, hypertension, dyslipemia and DGL levels $\geq-17 \%$ at baseline, and hematocrit, number of lymphocytes, alkaline phosphatase levels, NT-proBNP, VCAM and hs-TnT. The plot depicts the marginal effect of PICP on DGL when log2-transformed PICP is fit in the basal model. 


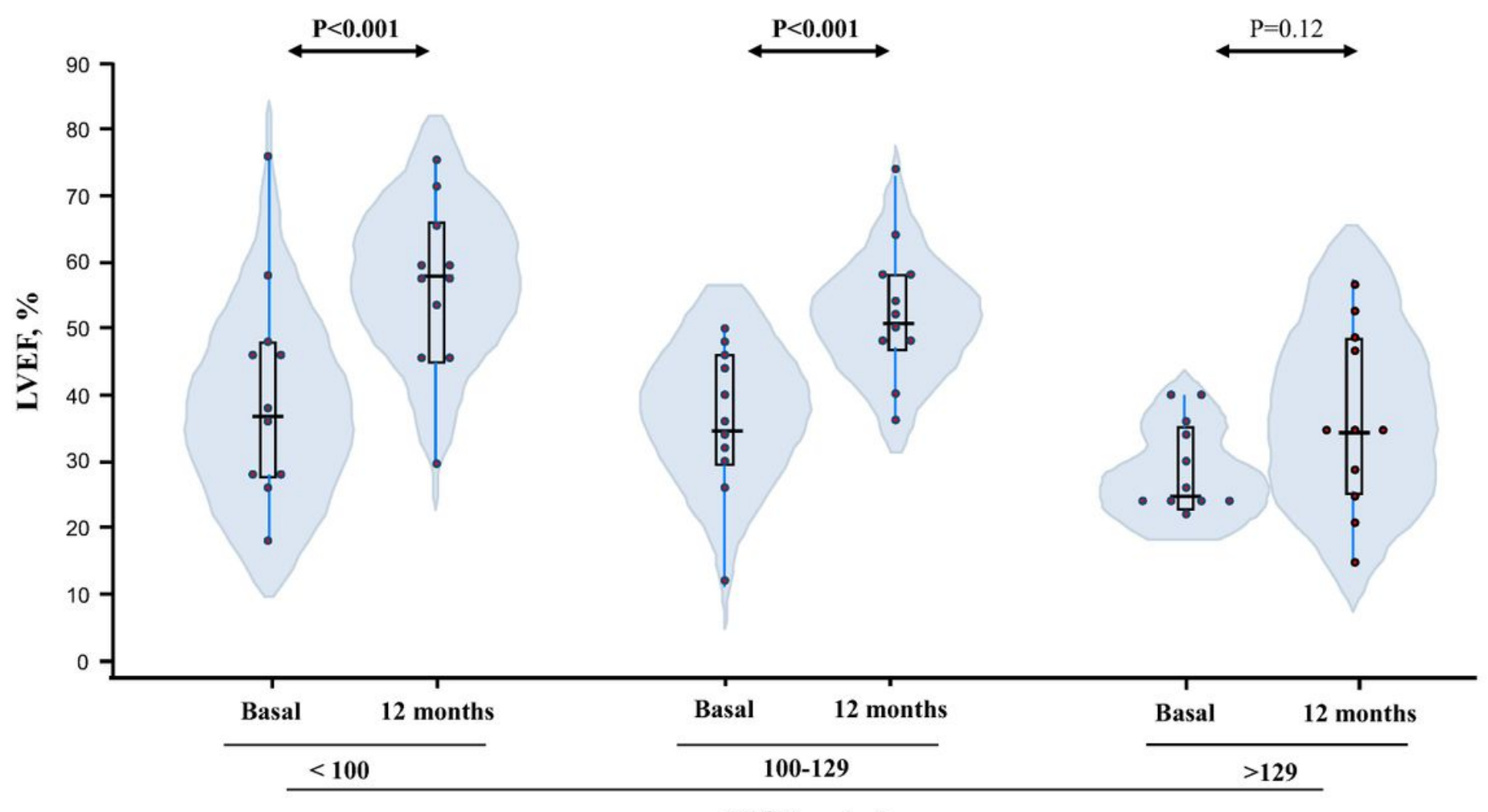

LVEF, \%

PICP, ng/mL
Mean \pm SD
$40.3 \pm 16.4 \quad 56.3 \pm 12.8$
$35.8 \pm 11.4 \quad 52.4 \pm 10.3$
$28.9 \pm 6.8$
$37.0 \pm 13.7$

Fig 3

Figure 3

Procollagen type I C-terminal propeptide (PICP) levels at baseline and 1-year changes in left ventricular ejection fraction (LVEF) in patients with heart failure attributed to anthracycline-based cancer chemotherapy (ACC-HF). Violin plots depict LVEF at baseline and after 12-months follow-up in ACC-HF patients categorized according to tertiles of baseline PICP. Red dots are individual values, horizontal lines indicate medians and boxes indicate interquartile ranges (linear mixed regression adjusted by LVEF basal values followed by pairwise contrast tests with a Bonferroni's-corrected $p$ value). 

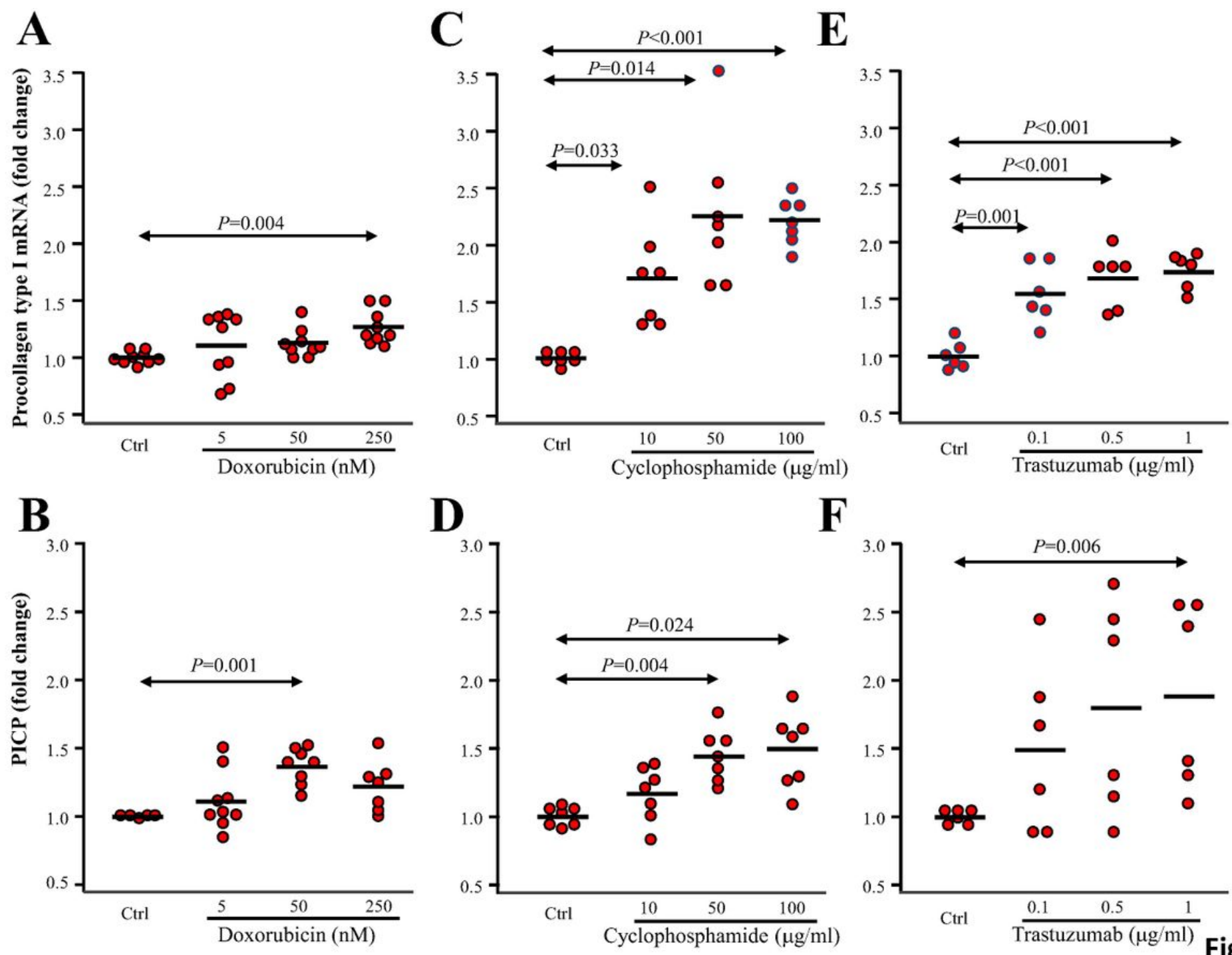

D
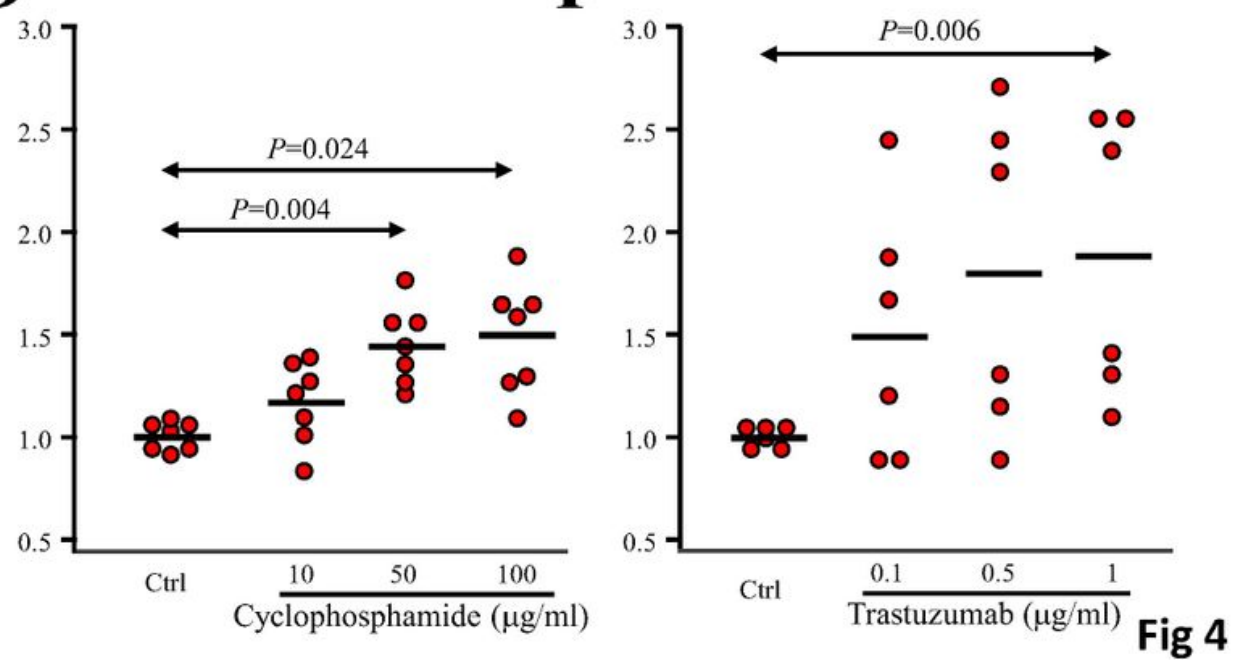

Figure 4

Cancer chemotherapy agents activate collagen metabolism in human cardiac fibroblasts. Dot plots represent fold changes in procollagen type I mRNA expression and in the extracellular procollagen type I C-terminal propeptide (PICP) content in human cardiac fibroblasts stimulated with or without 5, 50 and $250 \mathrm{nM}$ of doxorubicin (A,B, respectively; $\mathrm{n}=5-9,), 10,50$ and $100 \mu \mathrm{g} / \mathrm{mL}$ of cyclophosphamide (C,D, respectively; $n=7)$ and $0.1,0.5$ and $1 \mu \mathrm{g} / \mathrm{mL}$ of trastuzumab (E,F, respectively; $\mathrm{n}=6)$. Horizontal lines represent the mean (one-way ANOVA followed by Bonferroni or Tamhane's T2 [if inequality of variances] post hoc tests).

\section{Supplementary Files}

This is a list of supplementary files associated with this preprint. Click to download.

- CardiotoxMFSuppl260ct20.docx 